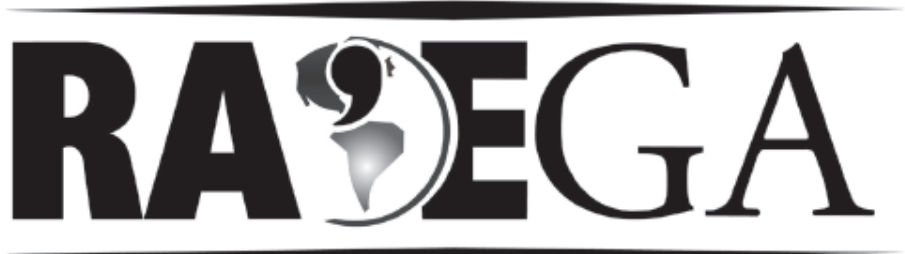

O ESPAÇO GEOGRÁFICO EM ANÁLISE

\title{
TÉCNICAS EM ESTUDOS BIOGEOGRÁFICOS
}

\section{TECHNIQUES IN BIOGEOGRAPHICAL STUDIES}

\author{
Yuri Tavares ROCHA ${ }^{1}$
}

\begin{abstract}
RESUMO
A Biogeografia utiliza técnicas para obter informações sobre os seres vivos e o meio físico com o qual interagem. As técnicas são escolhidas em função da escala espacial, da escala temporal, dos aspectos que estão sendo pesquisados e da escola biogeográfica. São utilizadas técnicas oriundas de vários campos da ciência, principalmente das Ciências Biológicas e da Terra, não existindo técnicas exclusivamente biogeográficas; porém, devem estar direcionadas à identificação das unidades espaciais de plantas e animais. Neste artigo, são descritas, resumidamente, algumas das técnicas aplicadas ao estudo da fauna e da flora e as mais utilizadas nas pesquisas biogeográficas.
\end{abstract}

Palavras-chave: Biogeografia; técnicas; fauna; flora.

\section{ABSTRACT}

The Biogeography uses techniques to obtain information about plants and animals and their environment. These techniques are chosen in function of the space scale, time scale, aspects that are being researched, and biogeographical approach. The techniques come of various scientific fields, mainly of the Earth and Biological Sciences. The techniques are directed to the identification of the space units of the plants and animals; the information generated by techniques must present geographical values. The techniques applied to the fauna and flora studies most used in the biogeographical studies are described in this paper.

Key words: Biogeography; techniques; fauna; flora.

\footnotetext{
${ }^{1}$ Eng. Agrônomo, Mestre e Doutor em Geografia Física, Professor Doutor do Departamento de Geografia, Faculdade de Filosofia, Letras e Ciências Humanas, Universidade de São Paulo. <yuritr@usp.br>
} 


\section{BIOGEOGRAFIA NO CONTEXTO DA GEOGRAFIA FÍSICA}

A Geografia Física é o ramo da Geografia que se preocupa com a natureza e estuda o conjunto dos elementos bióticos e abióticos presentes no espaço geográfico (CONTI, 1999). Realiza a análise espacial de todos os elementos e processos físicos que compõem o meio ambiente: energia, ar, água, clima, relevo, solos, animais, plantas e a própria Terra (CHRISTOPHERSON, 1997), podendo ser dividida em campos ou ramos, que estudam esses elementos e processos (BROWN, 1977).

A partir do final do século XVIII, Alexander von Humboldt desenvolveu os fundamentos da Geografia Física, da Biogeografia e da Geofísica, sem deixar de estudar os aspectos econômicos e políticos (CRUZ, 1985). Humboldt também foi um dos grandes responsáveis por colocar os conhecimentos biogeográficos numa posição destacada entre as ciências da natureza e da Terra (MEAZA, 2000). Outro grande geógrafo, William Morris Davis, no final do século XIX, defendia que a Geografia Física era o estudo do meio físico transformado pelo homem (CONTI, 1999). São considerados campos básicos da Geografia Física: Biogeografia, Climatologia, Geomorfologia, Hidrologia e Pedologia (Figura 1).

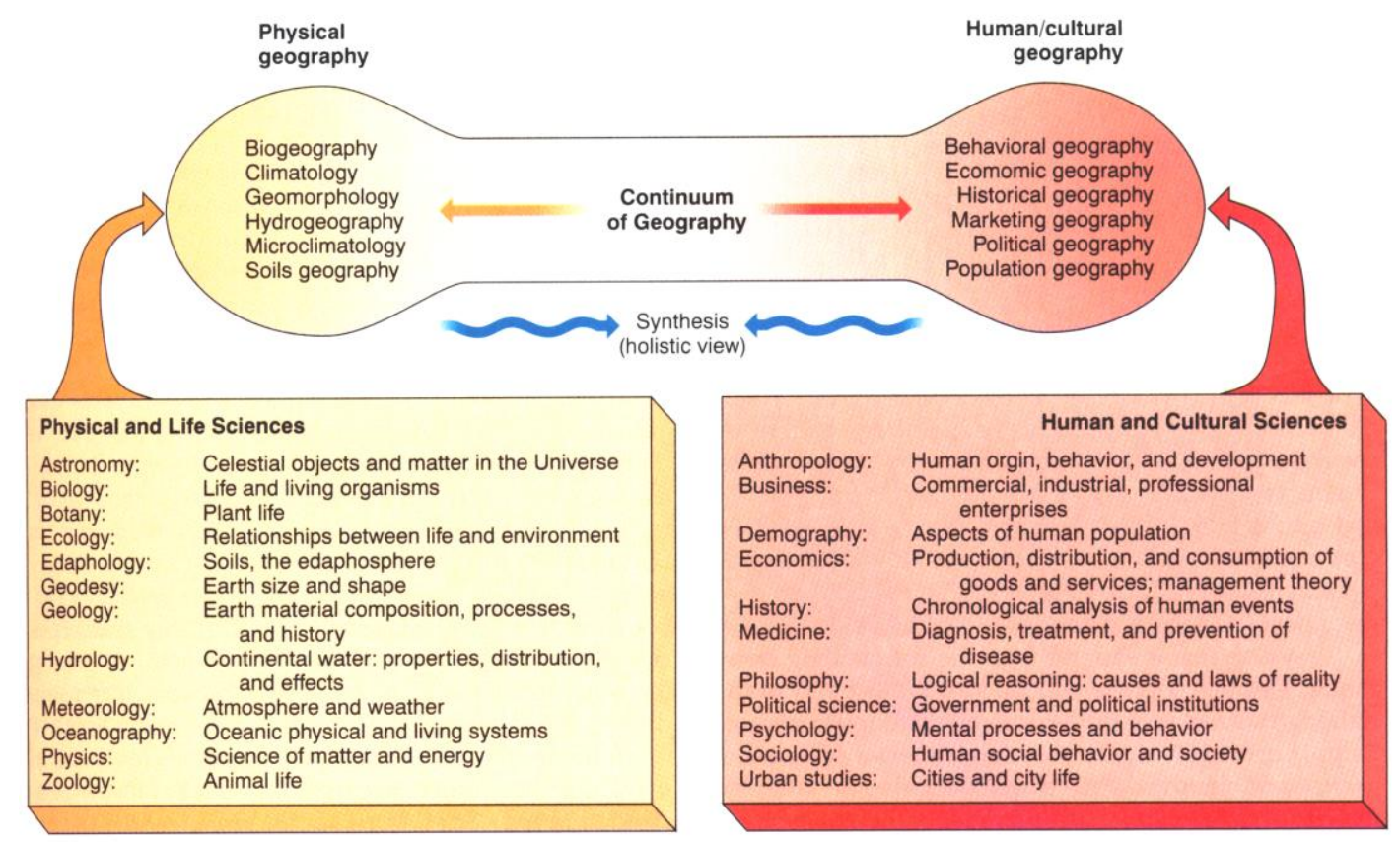

FIGURA 1 - CAMPOS DA GEOGRAFIA FÍSICA E DA HUMANA E AS CIÊNCIAS FÍSICAS, BIOLÓGICAS E HUMANAS RELACIONADAS COM A GEOGRAFIA (CHRISTOPHERSON, 1997). 
Os estudos geográficos não são feitos de forma isolada, pois apresentam inter-relações. Por exemplo, não se pode entender a distribuição de solos numa determinada área sem conhecer um pouco de geologia, relevo, clima e vegetação (MCKNIGHT; HESS, 2000). Além disso, o entendimento das complexas relações entre os elementos e processos físicos é importante para a sobrevivência do próprio homem, uma vez que os sistemas físicos da Terra e a sociedade humana são inter-relacionados e interdependentes (CHRISTOPHERSON, 1997).

Dessa forma, deve-se entender que, dentro da Geografia Física, a ação humana e os efeitos antrópicos são e devem ser considerados pelos geógrafos físicos; os efeitos do homem na derivação da natureza não são exclusividade dos estudos realizados pelos geógrafos ligados à Geografia Humana. Por exemplo, existe um ramo da Biogeografia que pesquisa a influência do homem na distribuição geográfica dos seres vivos e as conseqüências biogeográficas da domesticação de animais e do cultivo de plantas; é a Biogeografia Cultural (WATTS, 1971).

A Biogeografia procura documentar e compreender os modelos espaciais apresentados pela biodiversidade (BROWN; LOMOLINO, 1998). Estuda distribuição, adaptação, expansão e associações dos seres vivos nas escalas de tempo e de espaço, entendendo-se as causas e as modificações (KULHMANN, 1977), além da forma. Ou seja, procura entender a complexidade da vida no seu aspecto tridimensional, representado pelo triplo paralelismo: forma, espaço e tempo (COX; MOORE, 2000; SANTOS; AMORIM, 2007).

É a geografia dos seres vivos e dos sistemas e paisagens bióticas que eles configuram no meio ambiente; analisa as relações interativas que se estabelecem entre os seres vivos e os hábitats e os biogeótopos que os contêm, suas características fisionômicas e estruturais, sua dinâmica espacial e temporal e sua consideração como recurso e patrimônio natural e cultural, suscetíveis de valoração para efeitos de planejamento e gestão (MEAZA, 2000). 
A Biogeografia pode apresentar uma divisão básica relacionada ao tipo de ser vivo estudado: a Fitogeografia estuda a distribuição espacial das plantas ou da flora e suas correlações (FERNANDES, 2002); e, a Zoogeografia, a distribuição espacial dos animais ou da fauna (MÜLLER, 1974).

A Biogeografia agrega diferentes teorias, conceitos, procedimentos e técnicas de outros campos da ciência, principalmente das Ciências Biológicas e da Terra (Figura 2). Utiliza estudos de Paleontologia, Bioclimatologia, Ecologia, Fitossociologia, Geologia e Geormofologia (KUHLMANN, 1977), além de contribuições da Pedologia, Botânica e Zoologia, entre outras.

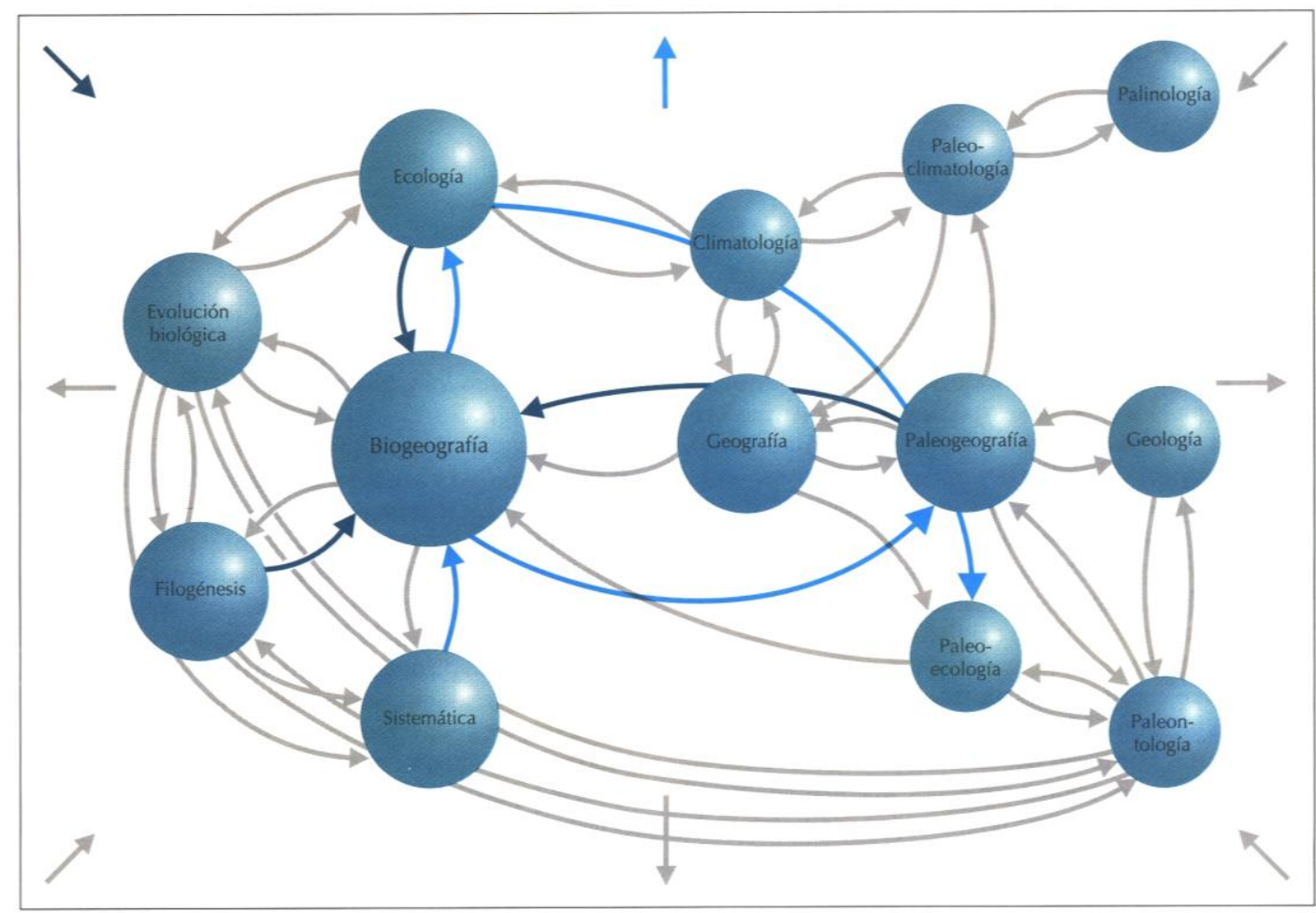

FIGURA. 2 - BIOGEOGRAFIA E AS CIÊNCIAS BIOLÓGICAS E DA TERRA (ZUNINO; ZULLINI, 2003).

Como a Biogeografia estuda as interações, organização e processos espaciais relacionados aos seres vivos, a Biogeografia é diferente da Biologia, Botânica, Zoologia e Ecologia (TROPPMAIR, 1987). Além disso, difere-se da maioria das disciplinas biológicas porque, em grande parte, está baseada na observação e comparação; na disponibilidade de dados de pesquisas realizadas em grandes áreas e por longos períodos; e, na interdisciplinaridade com várias disciplinas tradicionais (BROWN; LOMOLINO, 1998). Seu objetivo 
principal é a descrição e a análise das causas da distribuição dos seres vivos, tanto na atualidade quanto em sua história; é a síntese do estudo de padrões e processos existentes no aparente caos da multiplicidade de formas de vida (WATTS, 1971; ZUNINO; ZULLINI, 2003).

O elemento básico dos estudos biogeográficos é a área de distribuição dos seres vivos, que é a porção do espaço geográfico determinada pelas interrelações de uma espécie com este, ou seja, é a fração do espaço geográfico onde uma espécie está presente e interage com o ambiente (ZUNINO; ZULLINI, 2003). O estudo das áreas de distribuição é obrigatório na Biogeografia, sendo três aspectos importantes para seu entendimento: formais, bioecológicos e genético-dinâmicos (FERRERAS CHASCO; FIDALGO HIJANO, 1991).

Após meados do século $\mathrm{XX}$, alguns fatos revigoraram a Biogeografia: novas teorias matemáticas aplicadas à Ecologia, Evolução e Sistemática; aceitação da teoria da tectônica de placas; aumento do número de registros fósseis; novas tecnologias de computação, como o Sistema de Informação Geográfica (SIG), modelos de simulação, análises multivariantes e geoestatística; imagens de satélite e sensoreamento remoto; métodos filogenéticos e técnicas de Biologia Molecular; além das pesquisas sobre mecanismos limitantes das distribuições geográficas dos seres vivos (BROWN; LOMOLINO, 1998; ZUNINO; ZULLINI, 2003).

Atualmente, a Biogeografia tem se destacado na produção científica da Geografia e da Biologia. No período de 1945 a 2006, a palavra biogeografia apareceu registrada 3.456 vezes em títulos de artigos e revisões científicas e, considerando também os resumos e as palavras-chave, apenas no período de 1991 a 2006, 10.543 registros foram encontrados no Science Citation Index (SCl), destacando-se os seguintes periódicos científicos: Journal of Biogeography, Molecular Phylogenetics and Evolution, Molecular Ecology e Biological Journal of the Linnean Society; os países com maiores produções são: Estados Unidos, Reino Unido, Austrália, França, Alemanha, Espanha e Canadá (MORRONE; GUERRERO, 2008). 


\section{TÉCNICAS EM ESTUDOS BIOGEOGRÁFICOS}

As técnicas em estudos biogeográficos geram informações a respeito dos seres vivos e do meio físico com o qual interagem, contribuindo para a definição e o entendimento de suas distribuições geográficas no tempo e no espaço. As técnicas que estudam a fauna, a flora e o meio físico são utilizadas nos estudos biogeográficos. Assim, as técnicas oriundas da Geologia, Geomorfologia, Climatologia, Hidrologia e Pedologia também estão envolvidas nesses estudos biogeográficos, mas não serão tratadas neste artigo. Por exemplo, estudos geomorfológicos, que envolvem orientação de vertentes; pedológicos, que coletam amostras de solo; e, climáticos, que registram dados pluviométricos, são fundamentais para se correlacionar as características do meio físico com a distribuição de plantas e animais.

Os estudos biogeográficos da fauna e da flora procuram obter dados sobre distribuição geográfica, etologia, fenologia, relações, associações e coevoluções de animas e plantas, hábitat e dietas alimentares de animais, polinização, dispersão, etc. Por causa disso, Ecologia, Zoologia, Botânica, Palinologia, Genética e outras ciências também contribuem com técnicas para estudos biogeográficos, não existindo técnicas exclusivamente biogeográficas.

Apesar das técnicas serem de diferentes áreas, são direcionadas à identificação das unidades territoriais dos seres vivos, ou seja, a informação gerada pela aplicação de uma técnica sempre deve apresentar significado e valor geográficos (MEAZA, 2000). Além disso, as técnicas devem ser as mais adequadas para as escalas temporais e espaciais da pesquisa biogeográfica. Neste artigo, são descritas algumas técnicas aplicadas ao estudo da fauna e da flora e as mais utilizadas nas pesquisas biogeográficas.

\section{TÉCNICAS APLICADAS AO ESTUDO DE FAUNA}

São utilizadas para reconhecimento e amostragem de espécies, populações e comunidades animais que facilitam a compilação lógica e sistemática dos dados de interesse biogeográfico, gerando importantes informações zoogeográficas para diagnóstico e valoração de recursos faunísticos (LOZANO VALENCIA, 2000). 
Vale lembrar que a fauna é o topo da pirâmide ambiental e totalmente dependente de todos os elementos do sistema, co-evoluindo com ele e sendo o indicador mais sensível e confiável de seu estado de conservação e de sua dinâmica (LOZANO VALENCIA, 2000).

\section{Registros históricos e relatos de ocorrência}

Registros históricos de viajantes e naturalistas (Figura 3) e relatos de ocorrência presentes em obras iconográficas e literárias podem trazer informações de descrição, ocorrência e ou distribuição geográfica de animais. Os relatos de viagem de naturalistas são fontes de informações históricas importantes, uma vez que são geralmente ricos em descrições da cultura, do meio físico e da paisagem, conhecidos e percorridos pelos viajantes (ROCHA, 2005), além de apresentarem observações sobre plantas e animais e suas áreas de ocorrência.

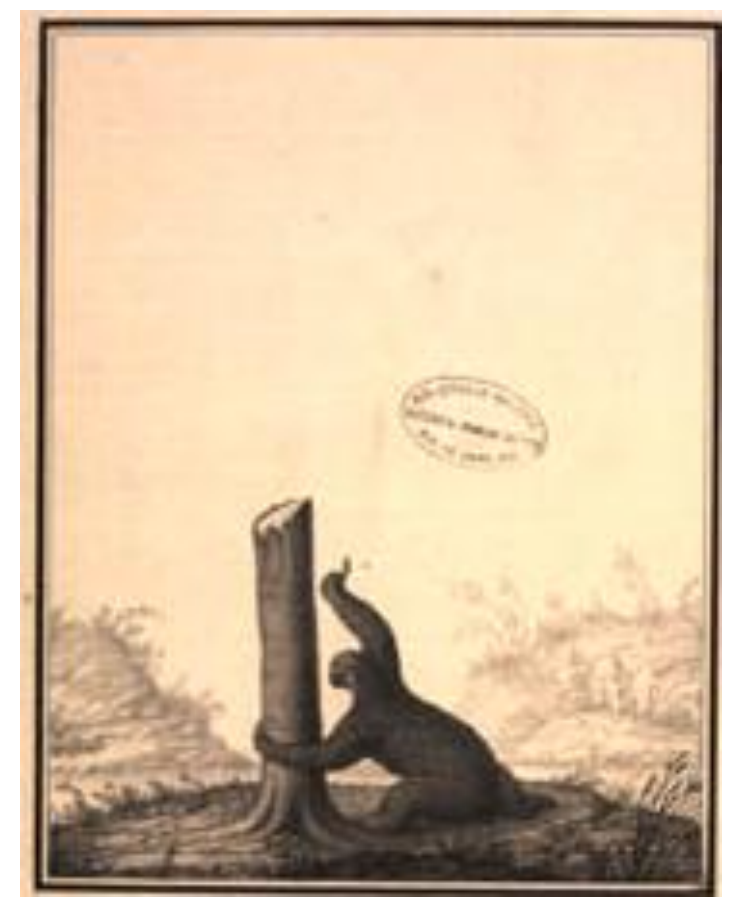

FIGURA 3 - ILUSTRAÇÃO DE BICHO-PREGUIÇA (Bradypus variegatus Schinz) PRODUZIDA PELA EXPEDIÇÃO DE ALEXANDRE RODRIGUES FERREIRA, NATURALISTA BRASILEIRO QUE REALIZOU VIAGEM NA AMAZÔNIA ENTRE 1783 E 1792 (BIBLIOTECA NACIONAL, 2011). 


\section{Coleções e museus zoológicos}

Também devem ser consultados museus e coleções de zoologia e de história natural que possuem acervos catalogados de animais ou partes de animais coletados e conservados, dispostos de acordo com um sistema de classificação, disponíveis para referência ou estudo, que podem conter milhares de exemplares. Essas coleções têm, quase sempre, suas amostras com data de coleta, nome do coletor, identificação científica e local de coleta, entre outras informações. São exemplos de instituições que têm coleções zoológicas: Museu de Zoologia da Universidade de São Paulo (Brasil), Smithsoniam National Museum of Natural History (Estados Unidos) e Muséum National d'Histoire Naturelle (França).

\section{Observação visual em campo e registro}

Há dificuldades para sua observação, uma vez que os animais possuem hábitos, movimentos e capacidades de deslocamento, além das reações que podem apresentar pela presença humana ou por suas estratégias de refúgio; por exemplo, alguns anfíbios, répteis e mamíferos podem desaparecer de uma área numa época do ano, os peixes podem não estar visíveis pela turbidez da água ou as aves podem estar ausentes, por terem migrado (LOZANO VALENCIA, 2000).

Mesmo com estas dificuldades, se for possível o contato visual, deve-se tentar fotografar ou desenhar e observar porte ou tamanho do animal; silhueta; presença de pêlos, escamas ou penas; coloração predominante; modo de deslocamento; etc. (LOZANO VALENCIA, 2000). Estas observações visuais podem ser úteis na identificação da espécie ou, pelo menos, da família; podem ser realizadas de forma constante e sistematizada, utilizadas para obter outras informações como, por exemplo, estimativa de sua densidade populacional (Tabela 1). 
TABELA 1 - ESTIMATIVA DE DENSIDADE POPULACIONAL DA RAPOSA-DOCAMPO (Lycalopex vetulus Lund) EM CAMPINÁPOLIS, ESTADO DO MATO GROSSO, BRASIL.

\begin{tabular}{cccccc}
\hline $\begin{array}{c}\text { Área } \\
\text { amostrada }^{1}\end{array}$ & $\begin{array}{c}\text { Número de } \\
\text { detecções }\end{array}$ & $\begin{array}{c}\text { Densidade } \\
\text { (ind.//km })^{2}\end{array}$ & $\begin{array}{c}\text { Erro } \\
\text { padrão }\end{array}$ & $\begin{array}{c}\text { Coeficiente } \\
\text { de variação } \\
(\%)\end{array}$ & $\begin{array}{c}\text { Intervalo de } \\
\text { confiança }^{3}\end{array}$ \\
\hline Campo sujo & 23 & 1,21 & 0,31 & 25,8 & $0,73-2,01$ \\
Pastagem & 52 & 4,28 & 1,01 & 23,7 & $2,69-6,82$ \\
\hline
\end{tabular}

FONTE: Rocha et al. (2008). Notas: ${ }^{1}$ Censos noturnos realizados em transectos lineares; ${ }^{2}$ Calculada pelo programa Distance $5.0 ;{ }^{3}$ Probabilidade de $95 \%$.

\section{Observação e registro de sons}

Juntamente com outros indícios ou vestígios dos animais, como se tratará adiante, o som produzido por eles também é importante para auxiliar em sua identificação. Os indícios são utilizados por métodos zoogeográficos alternativos, quando não se consegue a visualização do animal, dificultada pela mobilidade, pelo instinto de sobrevivência que o leva a se esconder ou fugir, pela mimetização e pelas condições ambientais (LOZANO VALENCIA, 2000).

A Bioacústica é a parte da Biologia que estuda o som produzido pelos animais e seu uso na comunicação, envolvendo comportamento, filogenia, ecologia, neurociência, taxonomia e ciências ambientais; ela também serve de material e de instrumento para outras pesquisas, principalmente para biólogos (VIELLIARD, 2004). As primeiras gravações de animais silvestres foram feitas em 1900, mas os registros sistemáticos começaram na década de 1950, resultando em coleções de gravações de sons de animais; atualmente, com os avanços tecnológicos, os sons podem ser registrados, armazenados e consultados (RANFT, 2004).

Cada espécie emite um som característico e sua identificação exige prática e conhecimento, podendo inclusive indicar sua densidade populacional; muitos invertebrados, anfíbios, mamíferos e, principalmente, aves produzem sons com a finalidade de marcar território, expulsar ou alertar competidores, emitir sinal de perigo e acasalar; tais sons apresentam duração, tonalidade e intensidade diferentes de acordo com sua função e tessitura (LOZANO VALENCIA, 2000). 
Os sons podem ser gravados em campo e, depois, comparados com arquivos de sons de animais já existentes; este procedimento é muito utilizado na identificação de aves. Estima-se que os principais arquivos tenham em torno de meio milhão de gravações (RANFT, 2004). O arquivo sonoro Neotropical do Laboratório de Bioacústica, da Universidade Estadual de Campinas (Unicamp), está entre as dez maiores coleções de sons de animais (VIELLIARD, 2004).

\section{Observação e análise do comportamento de animais}

Essa técnica é importante para a Biogeografia porque procura identificar as relações entre o comportamento animal e sua distribuição geográfica. São exemplos de pesquisadores dessa área: Konrad Lorenz, Jane Goodall e Richard Dawkins, entre outros.

Para a observação dos animais em campo, é necessário conhecer bem o animal, saber se é de fácil visualização ou não (Figura 4); se é necessário o observador usar camuflagem ou construir um abrigo camuflado; definir como será feito o deslocamento do observador para seguir o animal; se será utilizada ceva ou não, etc. Tudo deve ser feito para que a observação não afete o comportamento do animal, justamente o foco da técnica. Se a observação for invasiva ou perturbatória, alterará o comportamento do animal e será observada a reação do animal frente à perturbação e não seu comportamento habitual e inalterado. 


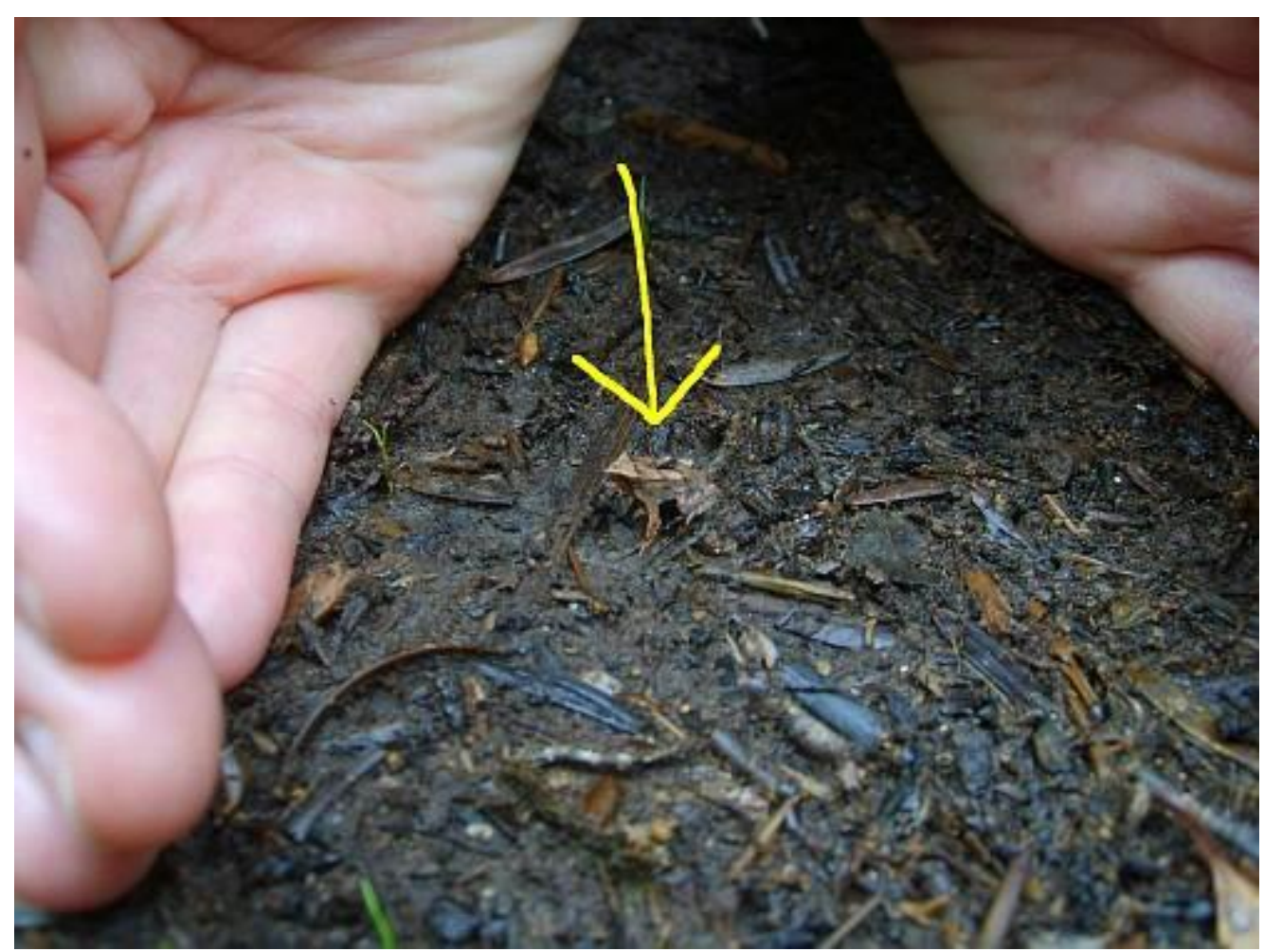

FIGURA 4 - SAPITO DE DARWIN (Rhinoderma darwinii Duméril \& Bibron), MINÚSCULO ANURO DAS FLORESTAS TEMPERADAS CHILENAS E ARGENTINAS, CAMUFLANDO-SE NA SERAPILHEIRA (FOTOGRAFIA: PABLO IBIETA/VIOLETA VUSCOVICH). É ESPÉCIE AMEAÇADA DE EXTINÇÃO, NA CATEGORIA "VULNERÁVEL", DE ACORDO COM A UNIÃO INTERNACIONAL PARA A CONSERVAÇÃO DA NATUREZA (IUCN, 2011).

\section{Captura, marcação, soltura e recaptura de animais}

Envolve a captura dos animais por redes, armadilhas ou gaiolas; marcação ou não com furos, anilhas ou plaquetas; e, recaptura dos mesmos animais, além do uso de rádio-telemetria, com colocação de radiotransmissores nos animais (Figura 5). Tais técnicas exigem maiores conhecimentos de biologia e medicina veterinária, para definir quais técnicas e equipamentos que não comprometerão o comportamento, a integridade física e a vida dos animais pesquisados. Os dados obtidos podem definir a área de distribuição dos animais, inclusive diferenciando áreas de alimentação, caça, repouso, etc. 


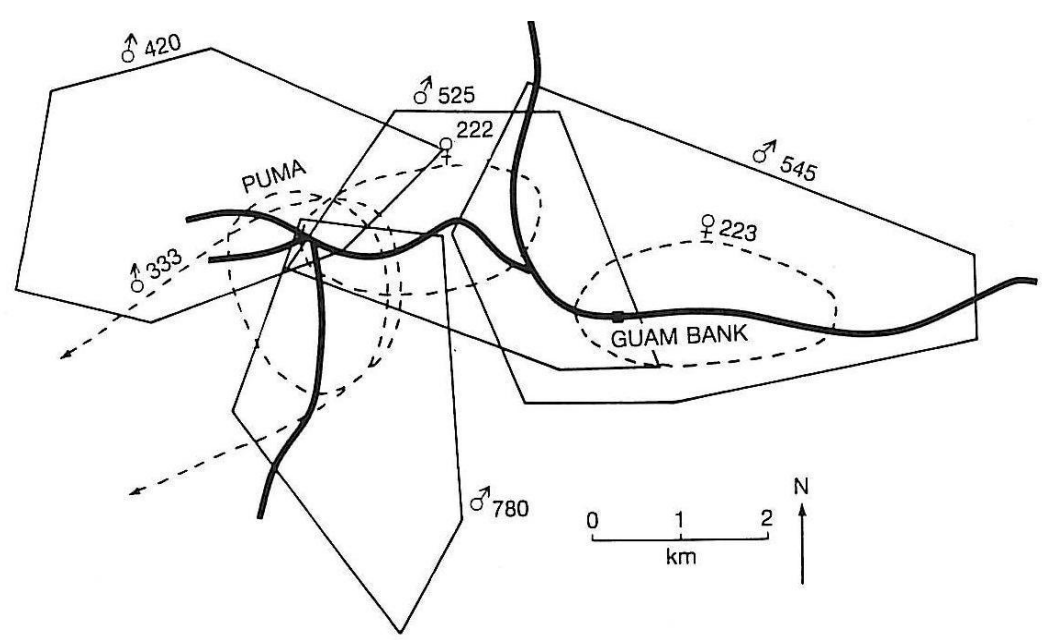

FIGURA 5 - ROTAS DE CINCO ONÇAS-PINTADAS MACHOS (Panthera onca L.), DUAS ONÇAS-PINTADAS FÊMEAS E UM PUMA (Puma concolor L.), NA BACIA DO RIO COCKSCOMB, BELIZE. LEGENDA: — ROTAS FEITAS POR RÁDIOTELEMETRIA; ----- ROTAS FEITAS POR VISUALIZAÇÃO; — ESTRADAS (RABINOWITZ; NOTTINGHAM JR, 1986).

\section{Armadilhas fotográficas}

Uma das técnicas menos invasivas para obter informações e registros visuais de animais é a utilização de armadilhas fotográficas, que são câmeras fotográficas colocadas em áreas ou trilhas de movimentação potencial de animais, ligadas a sensores de calor e movimento, que acionam o disparo da câmera quando os animais passam nas proximidades da armadilha fotográfica. Com as fotografias obtidas (Figura 6), pode-se fazer a identificação dos animais presentes na área estudada e obter outras informações (LYRA-JORGE et al., 2008).

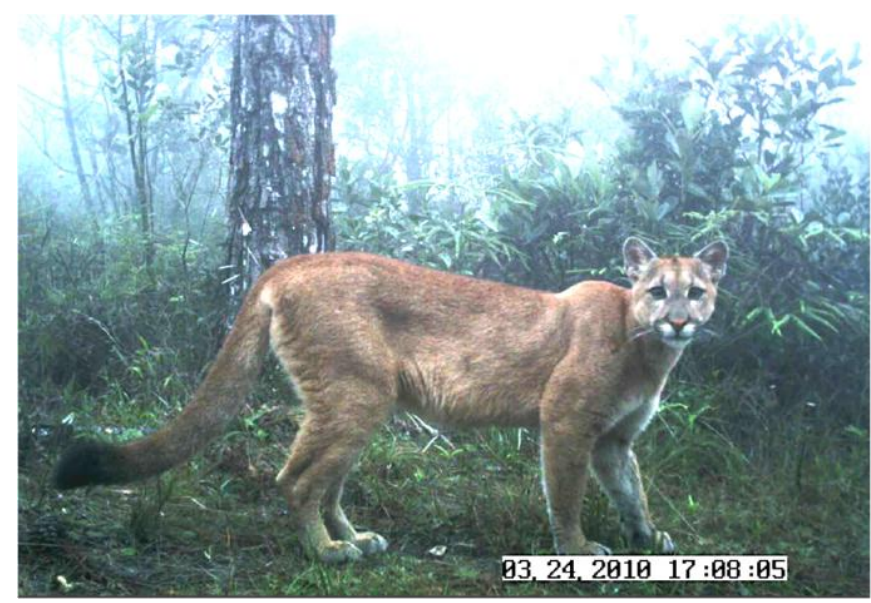

FIGURA 6 - FOTOGRAFIA DE ONÇA-PARDA (Puma concolor capricorniensis L.) OBTIDA POR ARMADILHA FOTOGRÁFICA (CAMERA TRAP DEPAVE 3), APA CAPIVARI-MONOS, SÃO PAULO/SP (SVMA, 2010). 


\section{Visualização e registro de pegadas e trilhas de animais}

Juntamente com os resíduos ou restos, que serão tratados mais adiante, as pegadas e as trilhas são indícios, sinais e evidências que os animais deixam nos locais que ocupam ou nos quais transitam. Para a identificação das pegadas, é imprescindível conhecimento sobre a morfologia corporal dos animais, principalmente das extremidades dos diversos grupos e espécies; as pegadas dos mamíferos são as que produzem melhores resultados na identificação pelas pegadas (LOZANO VALENCIA, 2000). Podem ser registradas por fotografia, desenho e ou moldes em gesso. Cada animal ou grupo de animais apresentam pegadas e marchas diferentes (Figura 7), que podem ser feitas por patas ou caudas.

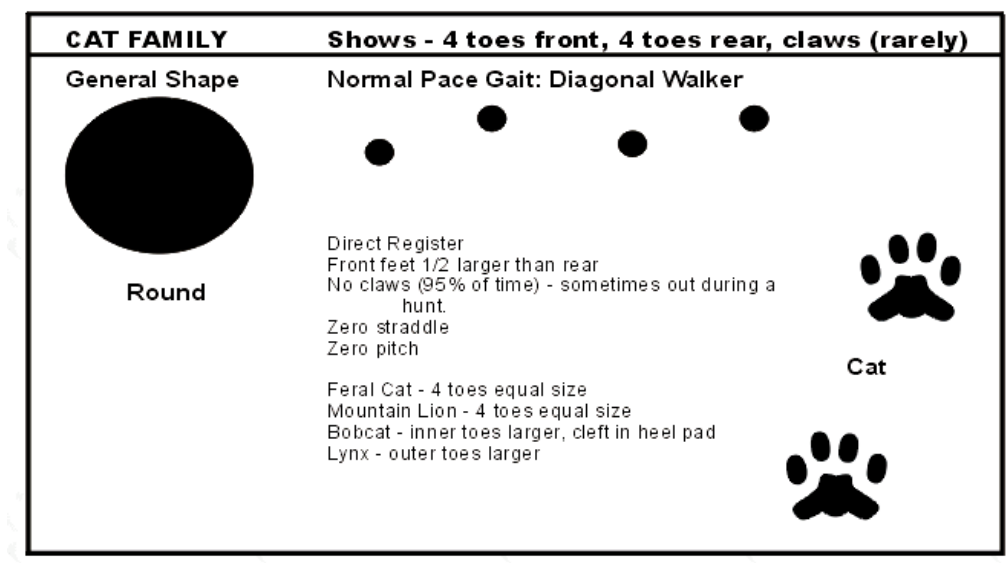

FIGURA 7 - PRINCIPAIS CARACTERÍSTICAS DAS PEGADAS DE FELINOS (USSARTF, 2011).

As características principais das pegadas observadas, tanto dianteiras quanto traseiras, são: forma principal; dimensões; número, formato e ângulo das marcas dos dedos, do calcanhar e das unhas, se existirem; profundidade e larguras superior e inferior; as características principais observadas da marcha: direção, comprimento e largura da passada e distância e ângulo entre as pegadas dianteiras e traseiras. Os tipos principais de marcha variam de acordo com a atividade do animal e são: passo, trote, galope e salto; além das pegadas e trilhas serem utilizadas para delimitar a área de distribuição de uma espécie, podem oferecer informações sobre seu modo de vida, alimentação, capacidade de movimento, densidade populacional, etc. (LOZANO VALENCIA, 2000). 


\section{Visualização e registro de resíduos ou restos de animais}

Os resíduos ou restos são, também, indícios da presença de animais numa área, que podem ser encontrados e registrados. Podem ser: regurgitos (pellets), que são resíduos da digestão regurgitados pelo predador, tais como penas, ossos, pêlos e cascas de suas presas; fezes, cuja análise pode indicar a dieta do animal, assim como os regurgitos (Tabela 2); urina, cujo odor é, na maioria dos animais, utilizado para marcar território; peles, pelagens ou exúvia de mudas ou ecdises ocasionadas pelo crescimento do animal ou pelo clima; e, ainda, pêlos, penas, carcaças (Figura 8), ossos e dentes, cuja análise pode auxiliar na identificação da espécie.

TABELA 2 - ITENS ALIMENTARES ENCONTRADOS NA ANÁLISE DE FEZES DO UIRAPURU-LARANJA (Pipra fasciicauda Hellmayr), ESTADO DO MATO GROSSO DO SUL, BRASIL.

\begin{tabular}{cccccc}
\hline Sexo & Insetos & Frutos & Insetos/frutos & Sementes & Outros \\
\hline 0 & 0 & $8(61 \%)$ & 0 & $4(31 \%)$ & $1(8 \%)$ \\
0 & $1(25 \%)$ & $2(50 \%)$ & 0 & $1(25 \%)$ & 0 \\
Ind. ${ }^{1}$ & 0 & $7(50 \%)$ & $2(14 \%)$ & $3(21 \%)$ & $2(14 \%)$ \\
\hline Total & 1 & 17 & 2 & 8 & 3 \\
\hline
\end{tabular}

FONTE: Piratelli; Pereira (2002). Nota: ${ }^{1}$ Indivíduos sem determinação de sexo.

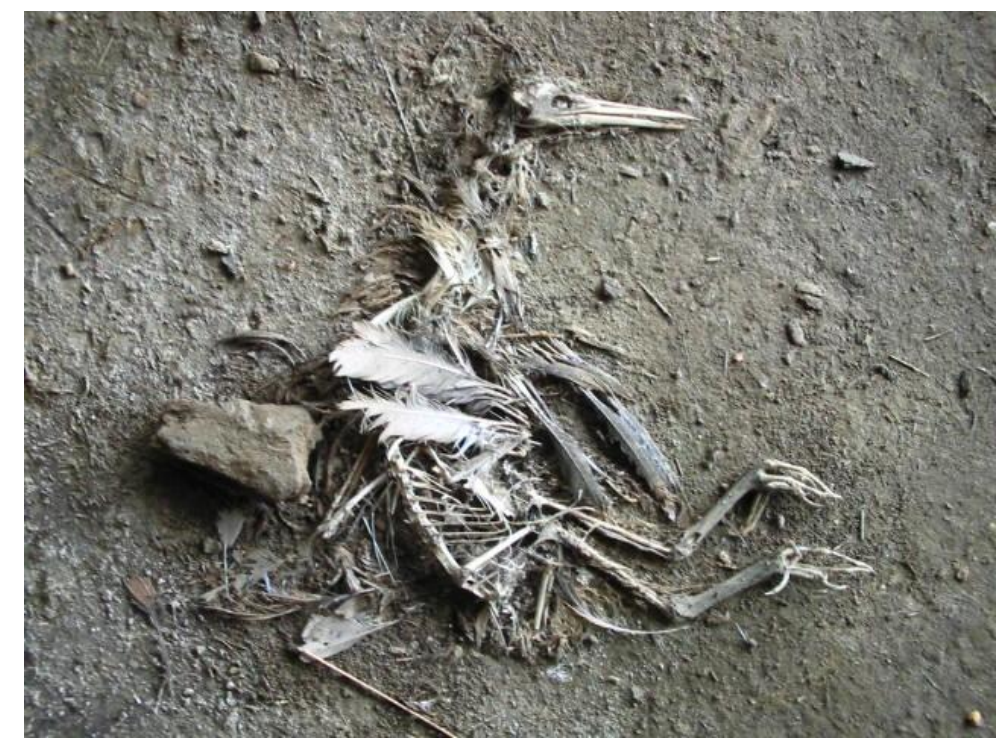

FIGURA 8 - CARCAÇA DE GARÇA-PEQUENA (Egretta thula Molina) COM ALGUMAS PENAS. ESPÉCIE QUE OCORRE NAS AMÉRICAS JUNTO A RIOS, LAGOS, BREJOS E MANGUES (FOTOGRAFIA: YURI TAVARES ROCHA). 
Outros resíduos que podem ser encontrados são restos de alimentação, como fragmentos de plantas, frutos ou sementes (herbívoros) e restos de corpos de animais (carnívoros), deixados no local de alimentação ou próximos a ninhos ou abrigos (LOZANO VALENCIA, 2000).

Por último, existem os fósseis, que podem ser divididos em: somatofósseis, fósseis de restos de corpos de animais; e, icnofósseis, fósseis de vestígios da atividade biológica, tais como fezes, pegadas, etc. Os fósseis são objetos de estudos da Paleontologia e da Biogeografia Histórica, exigindo técnicas muito especializadas, não tratadas neste artigo.

10. Visualização e registro de locais de repouso, refúgio, pouso, ninhos, tocas e abrigos de animais

Locais de repouso, refúgio e pouso, juntamente com ninhos, tocas e abrigos de animais podem indicar sua presença e sua área de distribuição, entre outras informações, mas exigem maior conhecimento e experiência para correlacioná-los com as espécies que os produziram. Os indícios pegadas, penas, pêlos, pele e dentes, entre outros, podem resultar numa identificação mais precisa do que ninhos, tocas, abrigos e esconderijos. Porém, nenhum vestígio ou indício deve ser menosprezado se for localizado e observado em campo.

\section{TÉCNICAS APLICADAS AO ESTUDO DE FLORA}

As técnicas mais utilizadas nos estudos de vegetação são descritas sucintamente a seguir, além de apresentarem maior relevância para pesquisas biogeográficas.

\section{Registros históricos e relatos de ocorrência}

Registros históricos de viajantes e naturalistas (Figura 9) e relatos de ocorrência presentes em obras iconográficas e literárias podem trazer informações de descrição, ocorrência e ou distribuição geográfica de plantas. 


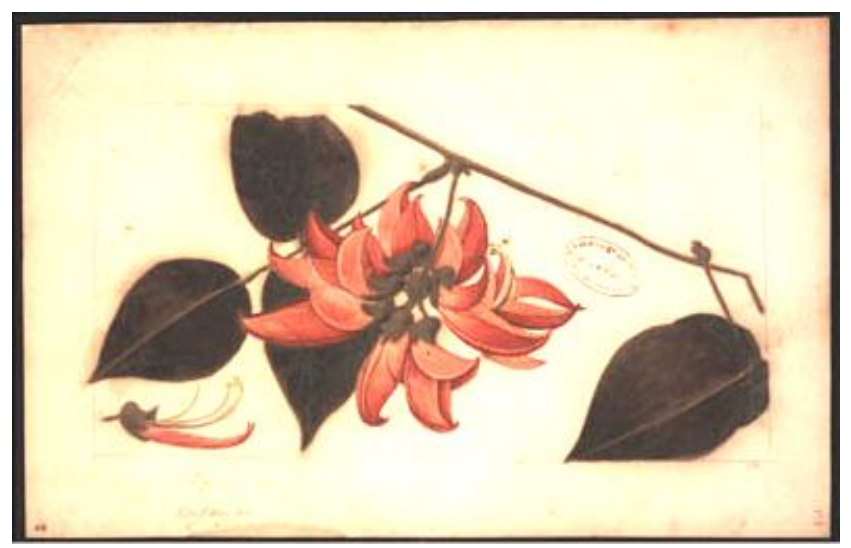

FIGURA 9 - ILUSTRAÇÃO DE ERITRINA-CRISTA-DE-GALO (Erythrina crista-galli L.) PRODUZIDA PELA EXPEDIÇÃO DE ALEXANDRE RODRIGUES FERREIRA, NATURALISTA BRASILEIRO QUE REALIZOU VIAGEM NA AMAZÔNIA ENTRE 1783 E 1792 (BIBLIOTECA NACIONAL, 2011).

\section{Consulta a herbários}

Herbário é uma coleção de plantas desidratadas, identificadas em sua maioria e dispostas de acordo com um sistema de classificação, disponíveis para referência ou estudo. Um herbário pode conter centenas de exemplares, que são chamados de exsicatas (Figura 10).

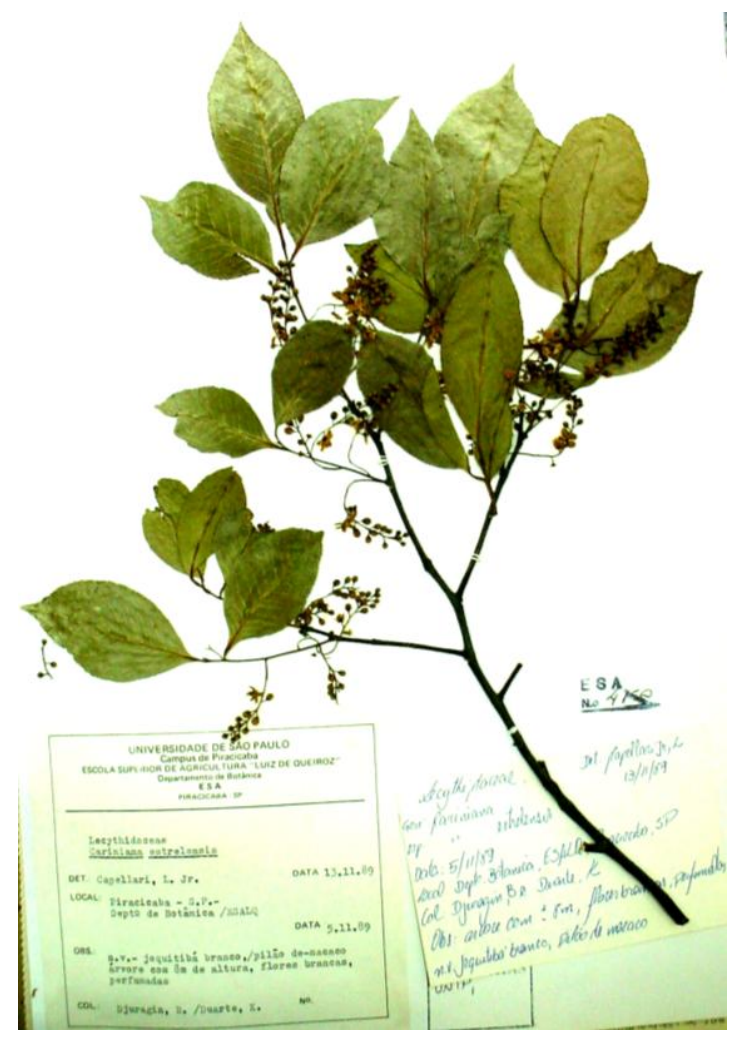

Figura 10 - EXSICATA DE JEQUITIBÁ-BRANCO (Cariniana estrellensis (Raddi) Kuntze) DO HERBÁRIO ESA/ESALQ/USP (FOTOGRAFIA: YURI TAVARES ROCHA). 
As plantas que estão num herbário foram coletadas, prensadas e secas por um processo centenário e simples chamado herborização, que consiste em fazer a desidratação da amostra de planta sob pressão constante, de modo que o resultado será uma amostra seca, importante para sua conservação, e reduzida a uma forma mais plana, facilitando seu armazenamento. São exemplos de instituições que possuem herbários com grande número de coletas armazenadas: Jardim Botânico do Rio de Janeiro (Brasil), New York Botanical Garden (Estados Unidos) e Royal Botanic Gardens (Kew, Inglaterra), entre outras.

3. Caracterização do estado de conservação, degradação, recuperação, sucessão ecológica ou regeneração da vegetação

Com base em informações já conhecidas sobre o aspecto natural da vegetação ou por comparação com a vegetação do entorno, podem ser feitas observações e interpretações a respeito de perturbações e alterações que afetaram a vegetação, tais como fogo, desmatamento, corte seletivo, movimento de massas, erupção, etc. (Figura 11). Para essa caracterização, é necessária grande experiência em fisionomia da vegetação e florística, itens tratados adiante.

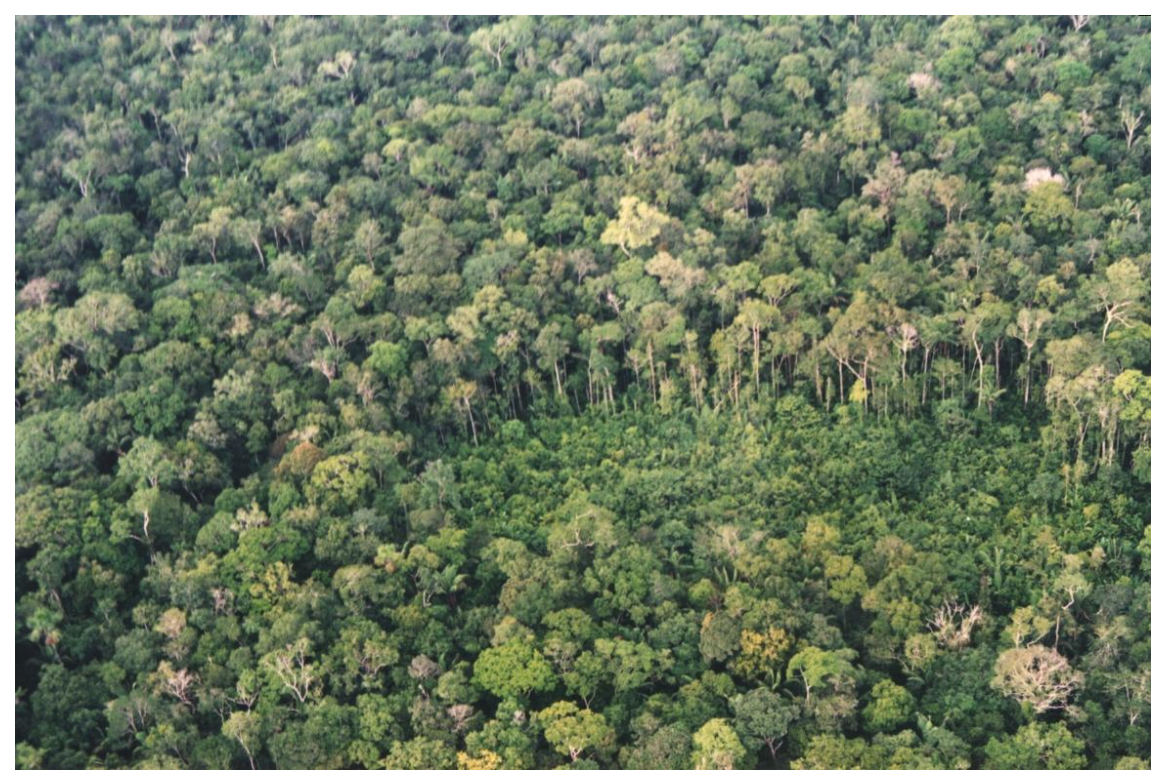

FIGURA 11 - CLAREIRA EM SUCESSÃO NATURAL NA FLORESTA AMAZÔNICA (FOTOGRAFIA: FELISBERTO CAVALHEIRO). 


\section{Fisionomia da vegetação}

É a característica mais visível, determinada em função, principalmente, da composição florística, do clima, do relevo, do solo e do uso e ocupação da terra; depende da disposição e da forma das espécies vegetais dominantes numa determinada área; permite entender a estrutura territorial da paisagem vegetal, baseiando-se: na diferenciação simples entre formas de organização das plantas, de acordo com porte arbóreo, arbustivo ou herbáceo; nos aspectos fenológicos; na forma das folhas; e, na continuidade espacial da vegetação (MEAZA, 2000).

Os estudos fisionômicos são adequados para os primeiros estudos da vegetação, orientados para a identificação das formações elementares existentes numa área e a sua distribuição em relação aos fatores ecológicos domintantes; são importantes para a diferenciação de unidades espaciais de vegetação em pequenas escalas, como os biomas ou área de condições ambientais contrastantes (AROZENA CONCEPCIÓN, 2000).

Dois componentes formam a fisionomia da vegetação: a estrutura vertical e a estrutura horizontal, cuja observação, registro e análise geram o perfil vertical e o perfil horizontal ou cobertura vegetal (Figura 12).

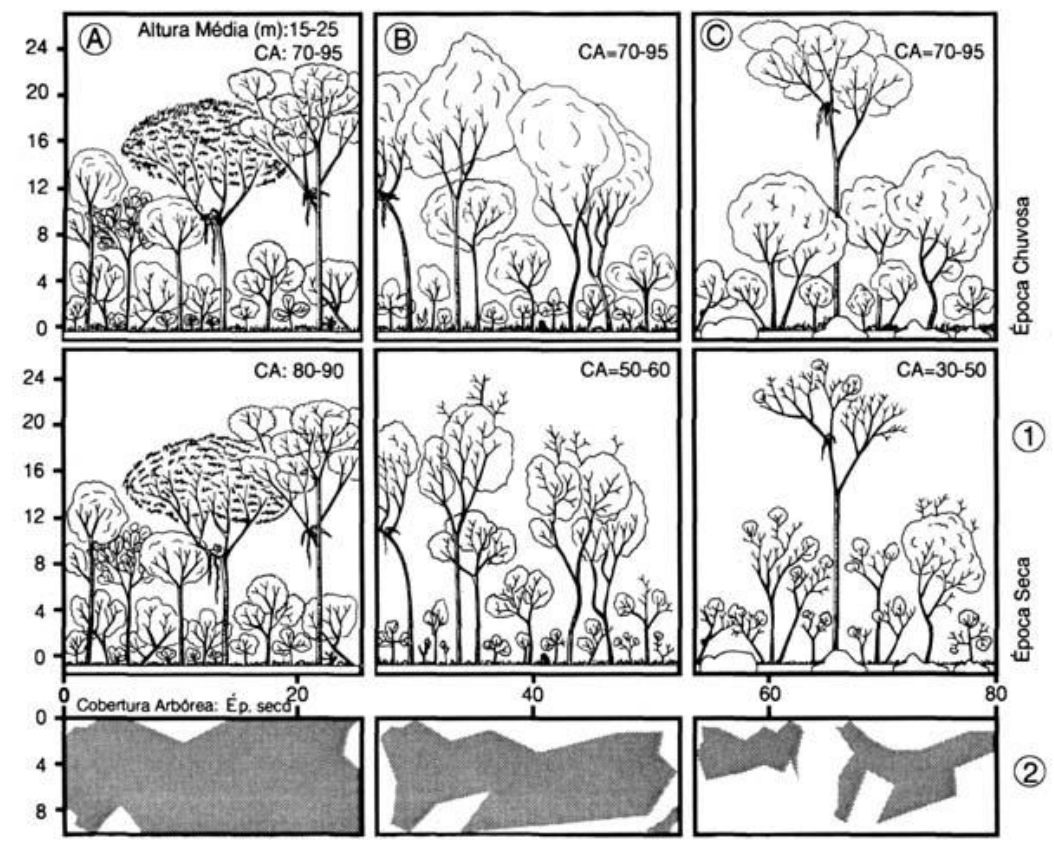

FIGURA 12 - PERFIL VERTICAL (1) E COBERTURA VEGETAL ARBÓREA (2) DE TRÊS MATAS SECAS (A, B, C) EM PERÍODOS DIFERENTES: ESTAÇÃO CHUVOSA E ESTAÇÃO SECA (RIBEIRO; WALTER, 2011). 
A estrutura vertical da vegetação é observada em sua estratificação, que deve ser baseada no conjunto de formas existentes na vegetação para identificar os estratos básicos, não se baseando apenas em níveis e intervalos de altura pré-determinados e padronizados; os principais estratos são: arbóreo, arborescente, arbustivo, subarbustivo e herbáceo (AROZENA CONCEPCIÓN, 2000).

A estrutura horizontal da vegetação apresenta uma informação secundária, complementado as informações do perfil vertical, indicando o caráter aberto, claro ou fechado da vegetação; considera os seguintes aspectos: grau de cobertura, densidade e continuidade (AROZENA CONCEPCIÓN, 2000).

A partir de estudos fisionômicos, podem ser realizados outros mais complexos, como estudos sobre composição florística e sobre dinâmica temporal e espacial das comunidades vegetais (MEAZA, 2000).

\section{Estudo florístico}

É a análise da composição florística da vegetação, realizada para compreender melhor como o componente vegetal contribui para a organização da paisagem; é importante para relacionar vegetações com fisionomias diferentes, mas com semelhanças geográficas e ecológicas e vice-versa (AROZENA CONCEPCIÓN, 2000).

Por exemplo, o campo-cerrado e o cerradão apresentam fisionomias diferentes, mas são semelhantes em termos geográficos, ecológicos e florísticos, já que são fisionomias do Domínio Brasileiro dos Cerrados, representante no Bioma das Formações Savânicas. Outro exemplo, inverso: uma floresta do Domínio Brasileiro Atlântico e outra do Amazônico podem apresentar fisionomias semelhantes, mas são diferentes em suas composições florísticas.

O levantamento florístico é uma ferramenta para o biogeógrafo, não um objetivo final; o geógrafo precisa conhecer a flora para entender mais profundamente as descontinuidades presentes na vegetação e suas explicações, da mesma forma que o geomorfólogo necessita estudar as rochas 
para compreender melhor as formas de relevo (AROZENA CONCEPCIÓN, 2000).

O estudo florístico consiste em identificar o maior número possível dos táxons que compõem a vegetação; para isso, são necessários conhecimentos da nomenclatura botânica, do manejo de guias e chaves florísticas e, muitas vezes, consulta a especialistas em botânica, os taxonomistas (AROZENA CONCEPCIÓN, 2000).

É feita a coleta do material botânico em campo, geralmente um ramo das plantas a serem identificadas com folhas, flores e ou frutos; esse material coletado passa pela herborização, processo já comentado, e, posteriormente, é identificado, preferencialmente, em nível de espécie. As espécies são organizadas em famílias botânicas, gerando a lista da composição florística da vegetação. Há índices que calculam as semelhanças ou similaridades florísticas de vegetações estudadas, tais como o Índice de Shannon ( $\left.\mathrm{H}^{\prime}\right)$ e o Índice de Simpson (D).

\section{Fitossociologia}

A caracterização fitossociológica das comunidades vegetais dos diferentes biomas e domínios é importante para a diferenciação das unidades espaciais da paisagem vegetal, além de complementar as observações geográficas e auxiliar na interpretação das descontinuidades da vegetação; porém, as informações fitossociológicas são referências e não suficientes para individualização e caracterização das unidades fitogeográficas (AROZENA CONCEPCIÓN, 2000).

O levantamento fitossociológico é quali-quantitativo porque procura conhecer quais são as plantas existentes na formação vegetal estudada e como estão arranjadas, existindo vários métodos de amostragem aplicados em campo, como por exemplo: método de parcelas, que podem ser contíguas ou não, retangulares (Figura 13), quadradas ou circulares; método de distâncias, que não utiliza parcelas, mas pontos de amostragem, também chamado método do quadrante centrado (Figura 14). Podem ser aplicados para estudos dos estratos arbóreo e arbustivo, principalmente, com a identificação e 
quantificação das espécies existentes e com as medidas coletadas em campo, sendo as principais: perímetro ou diâmetro da árvore na altura do peito $(1,3 \mathrm{~m}$, PAP ou DAP) e altura da árvore (h).

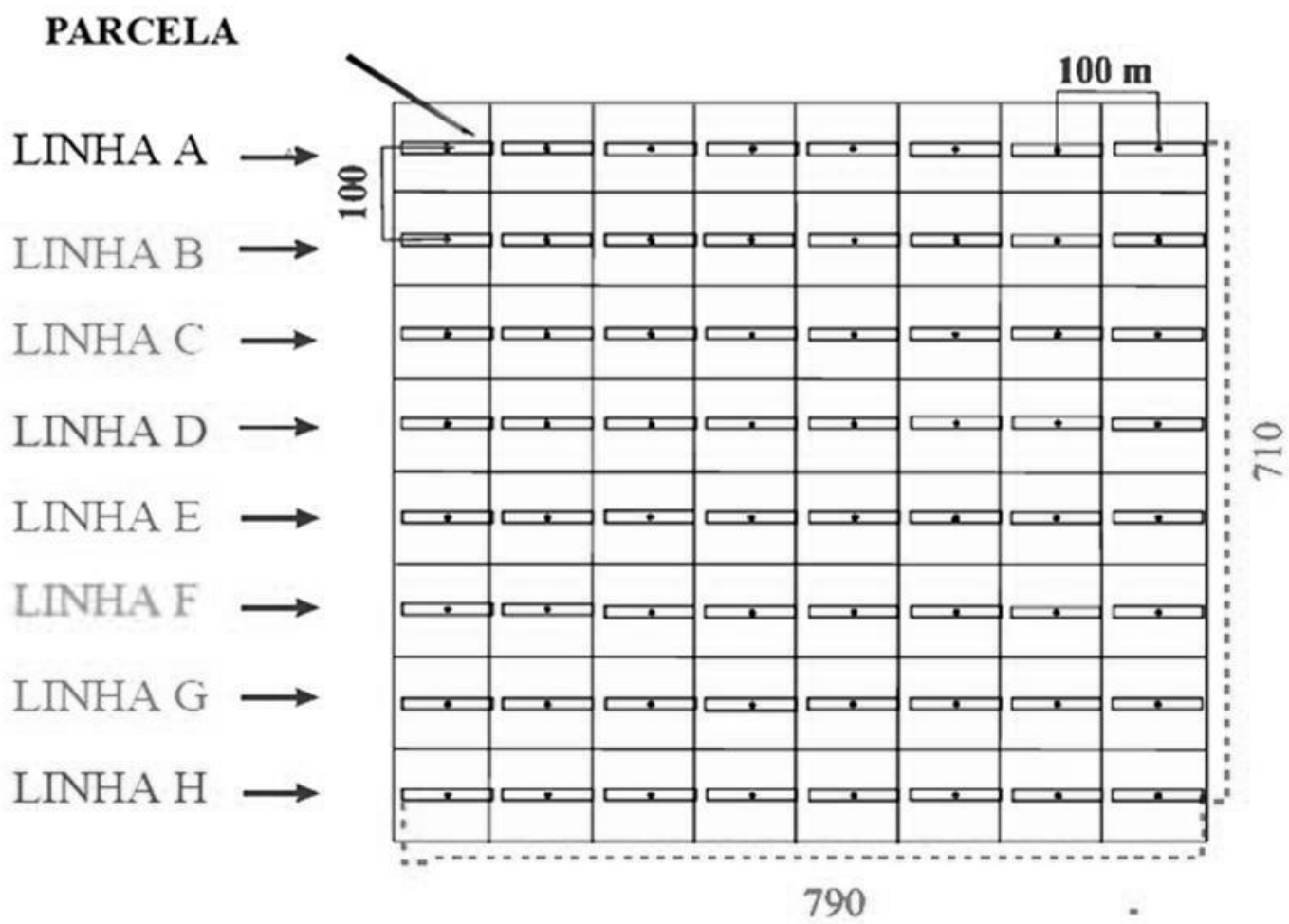

FIGURA 13 - DELIMITAÇÃO DE ÁREA AMOSTRAL PELO MÉTODO DE PARCELAS RETANGULARES (DIAS; COUTO, 2005).

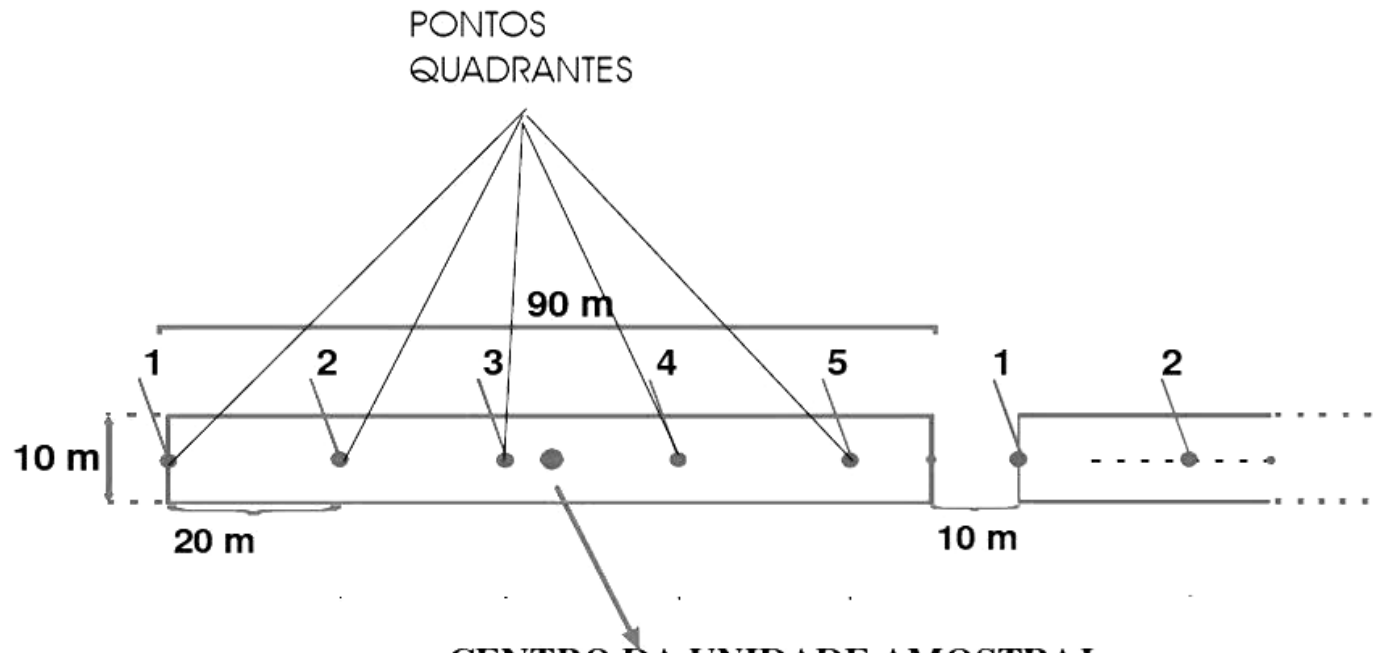

CENTRO DA UNIDADE AMOSTRAL

FIGURA 14 - DELIMITAÇÃO DE ÁREA AMOSTRAL PELO MÉTODO DOS PONTOS QUADRANTES (DIAS; COUTO, 2005). 
A partir dos dados coletados em campo, são obtidos os parâmetros fitossociológicos de cada espécie:

- Densidade (D): número de indivíduos da espécie por unidade de área ou ponto amostrado; se esse número for dividido pelo número total de espécies amostradas, gera a densidade relativa, expressa em porcentagem (\%);

- Freqüência $(F)$ : número de parcelas ou pontos amostrados em que a espécie foi encontrada; essa freqüência, dividida pela soma das freqüências de todas as espécies, resulta na freqüência relativa, expressa em porcentagem (\%);

- Dominância (Do): expressa pela área basal da espécie $\left(A B=\pi\right.$. $\left.(D A P)^{2} / 4\right)$; essa dominância, dividida pela soma das áreas basais de todas as espécies amostradas, resulta na dominância relativa, expressa em porcentagem (\%).

Outro parâmetro fitossociológico muito utilizado é o Índice de Valor de Importância (IVI), que é a soma das densidade, freqüência e dominância relativas (IVI $=\mathrm{DR}+\mathrm{FR}+\mathrm{DoR})$.

Os cálculos dos parâmetros fitossociológicos podem ser feitos com base as equações propostas por Mueller-Dombois e Ellemberg (1974) e por programas de computador, tais como SAS (programa estatístico) e FITOPAC (programa elaborado pelo Prof. Dr. George Shepherd/UNICAMP).

\section{Observação da fenologia}

Fazendo-se uma analogia com a observação do comportamento animal, a fenologia ou eventos fenológicos são as diferenças de aparência da planta, ou seja, quando ocorrem mudanças de seu aspecto tais como queda de folhas, floração, frutificação e dispersão de sementes. Estes eventos podem ocorrer em épocas diferentes para cada planta, auxiliando em sua identificação.

Juntamente com esses eventos, podem ser observados outros aspectos como visita de polinizadores, consumo de frutos por animais, agentes dispersores de sementes, etc. 


\section{CHAVES ANALÍTICAS OU DICOTÔMICAS}

Para qualquer estudo biogeográfico, tanto sobre fauna quanto flora, a fonte de informação sistemática, ou seja, a identificação da espécie ou do táxon estudado deve ser precisa; qualquer dúvida taxonômica pode se tornar um obstáculo para a pesquisa biogeográfica (SANTOS; AMORIM, 2007) ou colocar os dados e ou sua interpretação comprometidos cientificamente.

Além da consulta à bibliografia, a coleções botânicas ou zoológicas e do auxílio de taxonomistas botânicos ou zoólogos, uma das maneiras de se identificar o material coletado e ou observado em campo, tanto plantas quanto animais, em nível de espécie, gênero, família, etc. é a utilização de guias e chaves de identificação, analíticas ou dicotômicas, podendo ser a primeira tentativa de identificação, antes dos outros meios de identificação citados.

Estão baseadas nas características morfológicas das espécies e são elaboradas para que as características do material analisado sejam observadas e comparadas com as informações contidas na chave, agrupadas duas a duas. Nesta comparação, sempre tem que se escolher uma das duas opções apresentadas, que leva a outra comparação, também com duas opções, e assim sucessivamente, até se chegar a uma identificação possível, que necessita ser verificada de outras formas (Figura 15).

\footnotetext{
1-Apenas dois dedos funcionais em cada mão e três artelhos funcionais em cada pé.

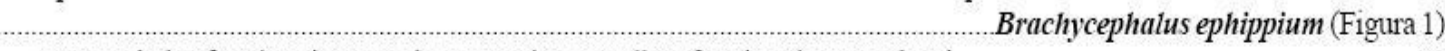

- Quatro dedos funcionais em cada mão e cinco artelhos funcionais em cada pé ......................................................2

2-Corpo robusto e ovóide, cabeça pequena e triangular (Figura 8b) .........................Elachistocleis cf. ovalis (Figura 8a)

- Forma do corpo não como acima.

3 - Ossificações distintas sobre a cabeça (cristas cefálicas).

- Cristas cefálicas indistintas/ausentes.

4-Apêndices cutâneos parecidos com "chifres" acima dos olhos

- Região acima dos olhos lisa ou com verrugas e cristas carnosas, mas sem "chifres"

Proceratophrys boiei (Figura 7j)

5-Sapos com 55 a $95 \mathrm{~mm}$ de comprimento rostro-cloacal (CRC). Maxilar superior com uma faixa estreita de coloração creme sob o olho. Glândulas parotóides (Figura 2a) com tamanho menor que $20 \%$ do CRC. Bufo ornatus (Figura 2b)

- Sapos com 100 a $170 \mathrm{~mm}$ de CRC. Sem faixa creme sob o olho. Glândulas parotóides maiores que $25 \%$ do CRC (na maioria das vezes, maiores que $30 \%$ ).

Bufo ictericus (Figura 2a)
}

FIGURA 15 - PARTE DA CHAVE DE IDENTIFICAÇÃO PARA ANUROS NA ÁREA DE PROTEÇÃO AMBIENTAL JUNDIAÍ, SERRA DO JAPI, ESTADO DE SÃO PAULO (RIBEIRO et al., 2005). 


\section{MAPEAMENTO EM ESTUDOS BIOGEOGRÁFICOS}

Como citado anteriormente, a Biogeografia espacializa a ocorrência dos seres vivos. Por isso, todas as técnicas descritas serão aplicadas num determinado ponto ou local que, com o avanço tecnológico cada vez mais acessível às pesquisas geográficas, deve ter suas coordenadas geográficas registradas por meio de um aparelho de Global Positioning System (GPS), dados necessários para o mapeamento da área de distribuição da espécie estudada.

A área de distribuição geográfica de uma espécie é a porção do espaço geográfico onde ela ocorre e tem inter-relações com este espaço ou ecossistema; a área de distribuição tem seu processo evolutivo: surge com o surgimento da espécie, modifica-se com o passar do tempo e desaparece se a espécie ocupante desaparecer (ZUNINO; ZULLINI, 2003).

Um dos aspectos fundamentais em qualquer mapeamento é a escolha da escala ou nível de resolução da representação dos dados (Figura 16). Nos mapeamentos biogeográficos, isso também é válido, sendo que uma escala errada pode levar a um excesso de detalhes na coleta, elaboração e representação dos dados e numa contribuição pequena em relação às necessidades reais e aos objetivos almejados pela pesquisa biogeográfica (BROWN; LOMOLINO, 1998; PANAREDA CLOPÉS, 2000).

A representação gráfica e cartográfica é fundamental para a análise espacial das plantas e animais, tanto nas diversas fases da pesquisa quanto na apresentação dos resultados finais (PANAREDA CLOPÉS, 2000).

O mapeamento biogeográfico produz mapas da área de distribuição de uma espécie a partir das coordenadas geográficas de suas ocorrências pontuais, sendo básico para outras pesquisas; geralmente, utiliza dados já existentes de herbários, levantamentos florísticos ou outras fontes; porém, os mapas produzidos podem apresentar zonas em branco, as quais podem representar a não ocorrência da espécie pesquisada ou a inexistência de dados a serem mapeados; daí a importância de trabalhos de campo sistemáticos para coletar o maior número de dados possível da área de 
ocorrência da espécie e preencher essas zonas em branco ou com lacunas de informações geográficas (PANAREDA CLOPÉS, 2000).

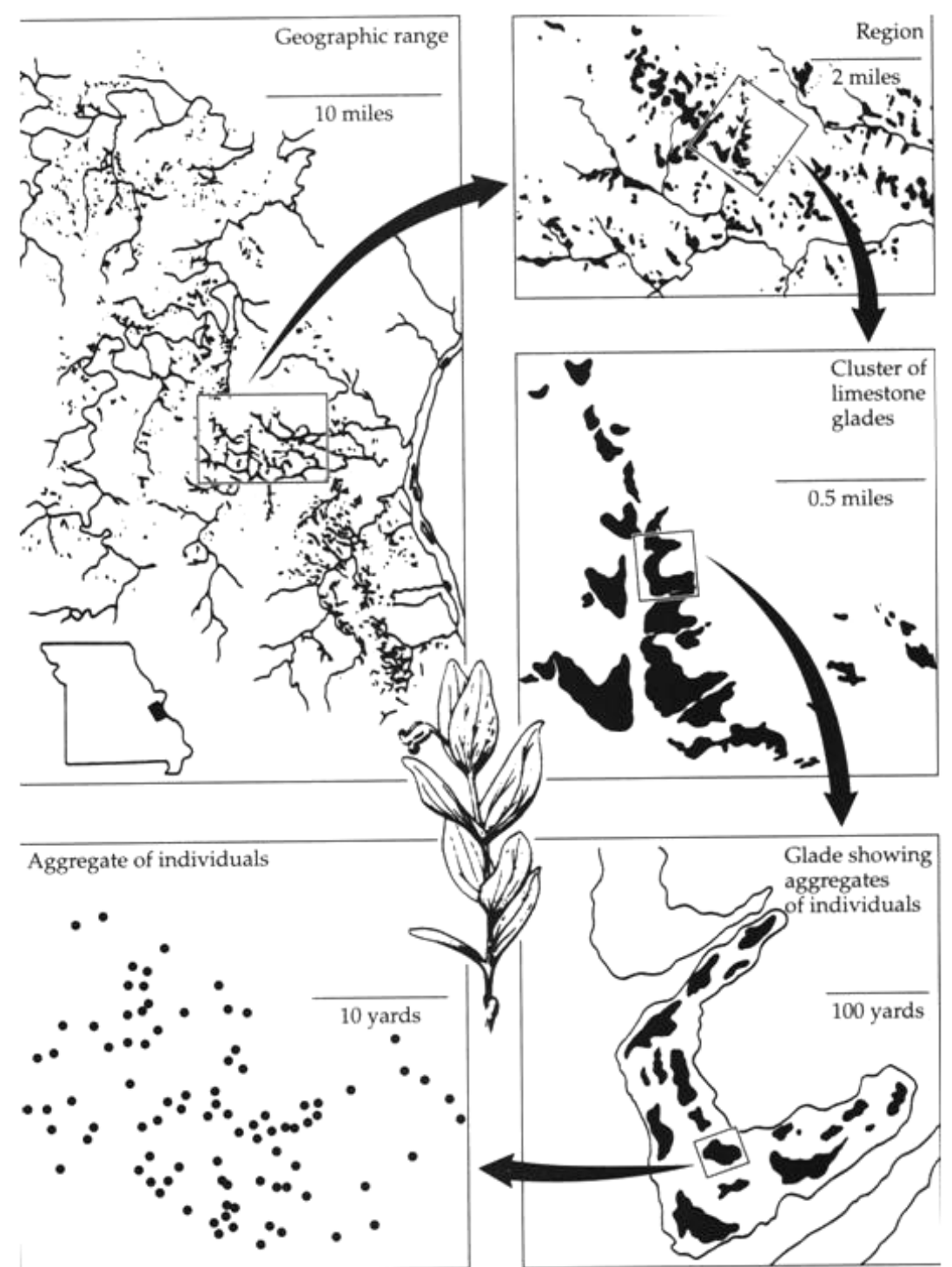

FIGURA 16 - DIFERENTES ESCALAS DA ÁREA DE DISTRIBUIÇÃO GEOGRÁFICA DE Clematis fremontii S. Watson NO ESTADO DE MISSOURI, ESTADOS UNIDOS (BROWN; LOMOLINO, 1998).

Um dos sistemas cartográficos é o sistema de pontos. Para a elaboração de um mapa de pontos (dot map), utiliza-se uma nuvem de pontos, que é a representação das localidades, áreas ou pontos nos quais foi registrada a ocorrência da espécie estudada (BROWN; LOMOLINO, 1998; ZUNINO; 
ZULLINI, 2003). Tal sistema permite representar com exatidão a distribuição de uma espécie, porém exige um grande esforço de campo para obter dados e evitar lacunas em excesso (PANAREDA CLOPÉS, 2000). Apresenta grande precisão porque apresenta os registros de coletas já realizadas de forma real e não superestima a área de distribuição para localidades onde se tenha dúvida sobre a ocorrência da espécie estudada (BROWN; LOMOLINO, 1998).

O sistema de manchas é outro sistema que delimita áreas de distribuição de uma espécie nas quais podem existir áreas que ainda se tem carência de informação ou a espécie ainda não foi localizada; mas, para a escala do mapa, estas ressalvas podem ser irrelevantes (PANAREDA CLOPÉS, 2000). As manchas procuram unir as informações de ocorrência fornecidas pelos pontos; podem ser delimitadas das seguintes formas: à mão livre, por diferentes métodos tais como do círculo mínimo, do raio médio a partir do centro geométrico e do mínimo polígono convexo; e, pelo método aerográfico, com auxílio do computador (ZUNINO; ZULLINI, 2003). Os processos de coleta de dados e de elaboração dos mapas de manchas são mais rápidos e econômicos, quando em comparação com o sistema de pontos, sendo a eficiência cartográfica semelhante, além de possibilitar uma visão mais completa e sinótica da distribuição de uma espécie (PANAREDA CLOPÉS, 2000).

Outro sistema é o da quadrícula em Universal Transversal de Mercator (UTM), que consiste em estabelecer quadrículas a partir de coordenadas geográficas UTM em forma de quadrados regulares, que podem ser subdivididos até a quadrícula mínima que se deseja, de acordo com a escala adotada para o mapeamento ou a área amostrada (PANAREDA CLOPÉS, 2000). As quadrículas podem apresentar apenas a ocorrência ou ausência da espécie ou trazer outras informações com o uso de símbolos diferentes como, por exemplo, indicar diferenças de abundância de determinada espécie (Figura 17): localizada, freqüente ou abundante (PANAREDA CLOPÉS, 2000; ZUNINO; ZULLINI, 2003). 

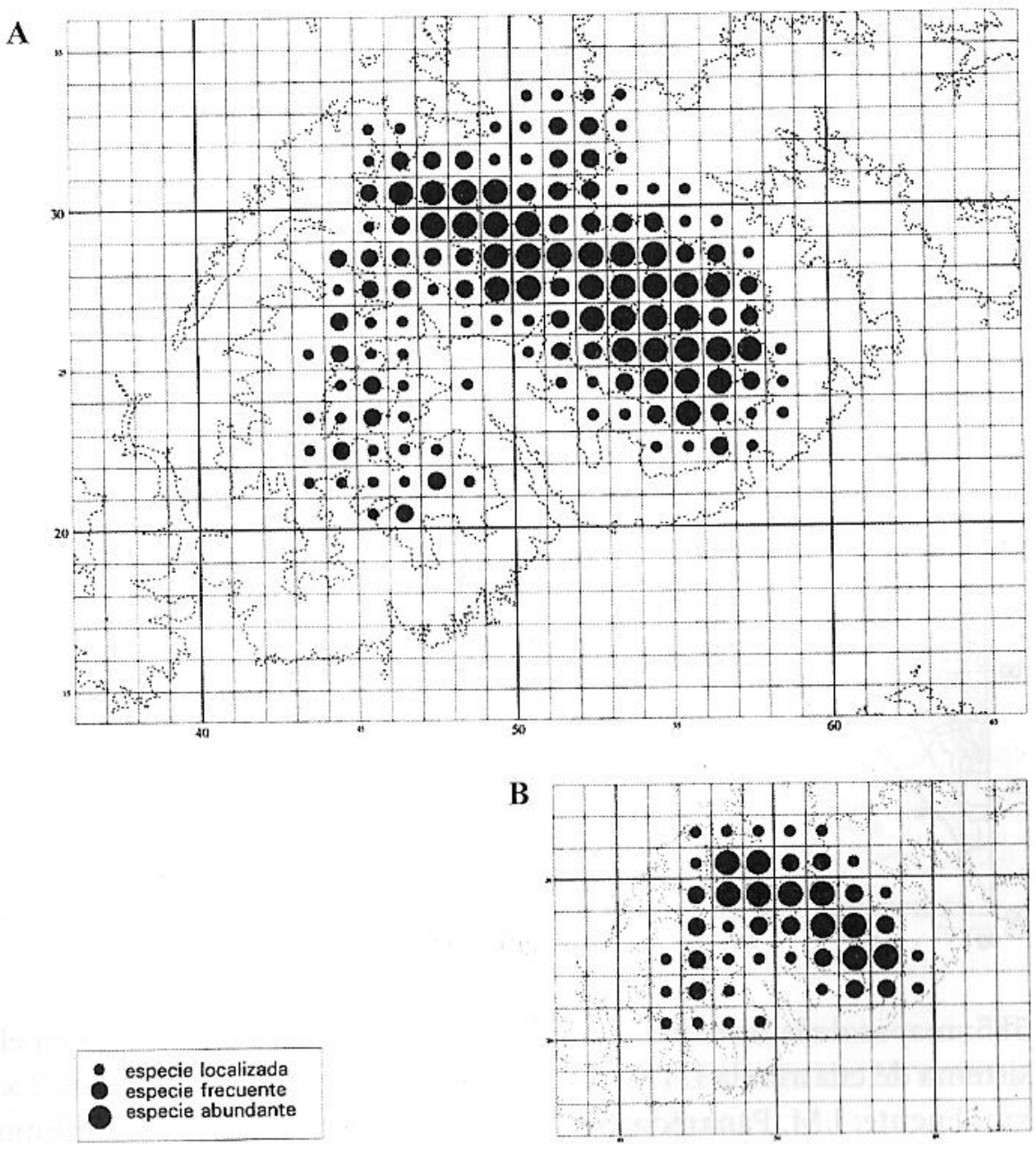

FIGURA 17 - MAPAS DE DISTRIBUIÇÃO GEOGRÁFICA DE FAIA (Fagus sylvatica L.), SERRA DE MONTSENY, ESPANHA. A - QUADRÍCULAS DE $1 \mathrm{X} 1 \mathrm{KM}$; B QUADRÍCULAS DE 2X2 KM (PANAREDA CLOPÉS, 2000).

Também existem mapeamentos que aliam informações sobre distribuição geográfica de espécies com diversas outras informações, como diversidade biológica, fronteiras geopolíticas, etc., utilizando métodos de proporcionalidade e distorção na representação cartográfica (Figura 19), como o método densityequalizing maps, que produz mapas úteis, elegantes e de fácil compreensão (GASTNER; NEWMAN, 2004).

Vale ressaltar que o sistema de mapeamento deve ser escolhido em função dos objetivos da pesquisa, das características pré-conhecidas da espécie estudada, da escala adotada para o mapeamento biogeográfico, dos 
dados de distribuição geográfica existentes e do esforço de campo que será despendido.

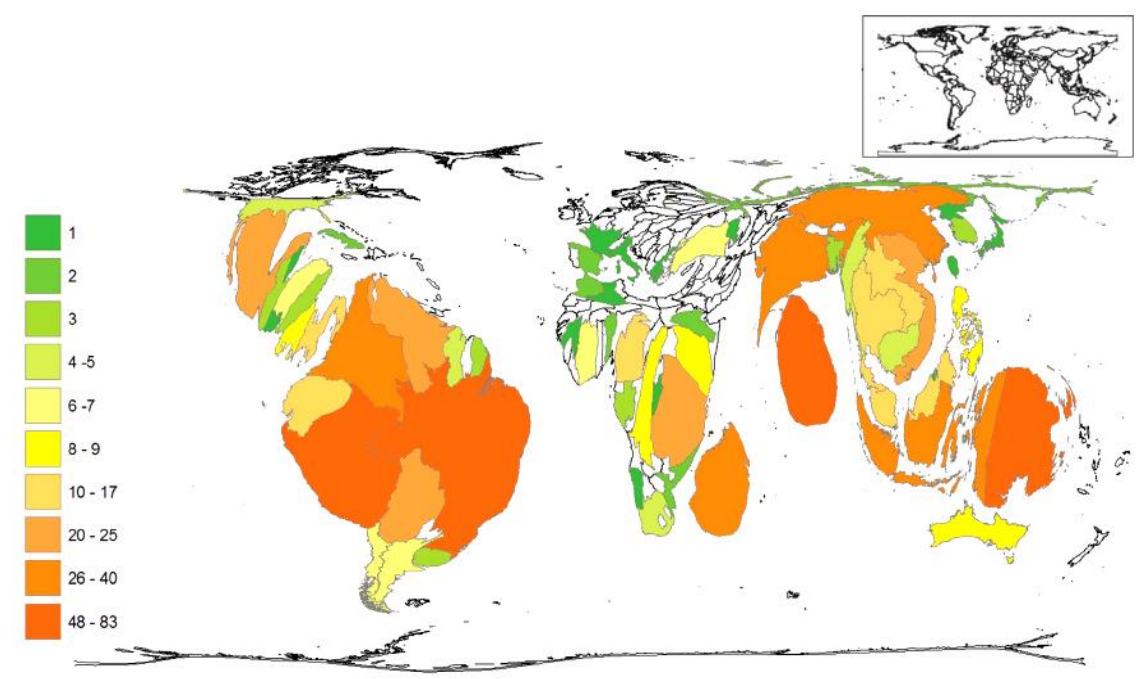

FIGURA 19 - DISTRIBUIÇÃO DE ESPÉCIES DE ANFÍBIOS DESCOBERTOS E NOMEADOS ENTRE 2004 E 2007 UTILIZANDO DENSITY-EQUALIZING METHOD; A LEGENDA INDICA O NÚMERO DE ESPÉCIES NOVAS POR PAÍS (WAKE; VREDENBURG, 2008).

\section{REFERÊNCIAS}

AROZENA CONCEPCIÓN, M. E. Estrucutra de la vegetación. In: MEAZA, G (Ed.) Metodologia y prática de la Biogeografía. Barcelona: Ediciones del Serbal, 2000. p. 77-146.

BIBLIOTECA NACIONAL. Coleção Alexandre Rodrigues Ferreira. Disponível em:<http://bndigital.bn.br/projetos/alexandre/galeria.htm>. Acesso em: 22/02/2011.

BROW, E. H. A. Geografia Física, seu conteúdo e suas relações. Boletim Geográfico, Rio de Janeiro, v. 35, n. 254, p. 14-2, 1977.

BROWN, J. H.; LOMOLINO, M. V. Biogeography. Sunderland: Sinauer, 1998.

CHRISTOPHERSON, R. W. Geosystem: an introduction to physical Geography. Upper Saddle River: Prentice -Hall, 1997.

CONTI, J. B. A Geografia Física e as relações sociedade-natureza no mundo tropical. In: CARLOS, A. F. A. (Org.) Novos caminhos da Geografia. São Paulo: Contexto, 1999. p. 9-26.

COX, C. B.; MOORE, P. D. Biogeography: an ecological and evolutionary approach. London: Blackwell, 2000. 
CRUZ, O. A Geografia Física, o geossistema, a paisagem e os estudos dos processos geomorfológicos. Boletim de Geografia Teorética, Rio Claro, v. 15, n. 29-30, p. 53-62, 1985.

DIAS, A. C.; COUTO, H. T. Z. Comparação de métodos de amostragem na floresta ombrófila densa, Parque Estadual Carlos Botelho (SP). Revista do Instituto Florestal, São Paulo, v. 17, n. 1, p. 63-72, 2005.

FERNANDES, A. Fitogeografia brasileira. Fortaleza: Multigraf, 2002.

FERRERAS CHASCO, C.; FIDALGO HIJANO, C. E. Biogeografía $y$ Edafogeografía. Madrid: Sintesis, 1991.

GASTNER, M. T.; NEWMAN, M. E. J. Diffusion-based method for producing density-equalizing maps. Proceedings of the National Academy of Sciences, Washington, v. 101, n. 20, p. 7499-7504, 2004.

IUCN. Red List. Disponível em:<http://www.iucnredlist.org/apps/redlist/details/19513/0>. Acesso em: 22/02/2011.

KUHLMANN, E. Noções de Biogeografia. Boletim Geográfico, Rio de Janeiro, v. 35, n. 254 , p. 48-111, 1977.

LOZANO VALENCIA, P. Métodos y técnicas em zoogeografía. In: MEAZA, G (Ed.) Metodologia y prática de la Biogeografía. Barcelona: Ediciones del Serbal, 2000. p. 319-374.

LYRA-JORGE, M. C.; CIOCHETI, G.; PIVELLO, V. R. Carnivore mammals in a fragmented landscape in northeast of São Paulo State, Brazil. Biodiversity and Conservation, Dordrecht, v. 17, n. 7, p. 1573-1580, 2008.

McKNIGHT, T. L.; HESS, D. Physical Geography: a landscape appreciation. Upper Saddle River: Prentice-Hall, 2000.

MEAZA, G. Metodologia y prática de la Biogeografía. Barcelona: Ediciones del Serbal, 2000.

MORRONE, J. J.; GUERRERO, J. C. General trends in world biogeographic literature: a preliminary bibliometric analysis. Revista Brasileira de Entomologia, Curitiba, v. 52, n. 4, p. 493-499, 2008.

MUELLER-DOMBOIS, D.; ELLEMBERG, H. Aims and methods of vegetation ecology. New York: Wiley \& Sons, 1974.

MÜLLER, P. Aspects of Zoogeography. Hague: Junk, 1974.

PANAREDA CLOPÉS, J. M. Cartografía y representación fitogeográfica. In: MEAZA, G. (Ed.) Metodologia y prática de la Biogeografía. Barcelona: Ediciones del Serbal, 2000. p. 275-316. 
PIRATELLI, A.; PEREIRA, M. R. Dieta de aves na região leste de Mato Grosso do Sul, Brasil. Ararajuba, São Paulo, v. 10, n. 2, p. 131-139, 2002.

RABINOWITZ, A. R.; NOTTINGHAM JR., B. G. Ecology and behaviour of the jaguar (Panthera onca) in Belize, Central America. Journal of Zoology, Oxford, v. 210, p. 149-159, 1986.

RANFT, R. Natural sound archives: past, present and future. Anais da Academia Brasileira de Ciências, Rio de Janeiro, v. 76, n. 2, p. 456-460, 2004.

RIBEIRO, J. F.; WALTER, B. M. T. Mata seca. Disponível em:<http://www.agencia.cnptia.embrapa.br/Agencia16/AG01/arvore/AG01 67 911200585234.html >. Acesso em: 22/02/2011.

RIBEIRO, R. S.; EGITO, G. T. B. T.; HADDAD, C. F. B. Chave de identificação: anfíbios anuros da vertente de Jundiaí da Serra do Japi, Estado de São Paulo. Biota Neotropica, Campinas, v. 5, n. 2, p. 235-247, 2005.

ROCHA, E. C. et al. Densidade populacional de raposa-do-campo Lycalopex vetulus (Carnivora, Canidae) em áreas de pastagem e campo sujo, Campinápolis, Mato Grosso, Brasil. Iheringia - Série Zoológica, Porto Alegre, v. 98 , n. 1, p. 78-83, 2008.

ROCHA, Y. T. Fontes históricas e pesquisas geográficas: relatos de viajantes, iconografia e cartografia. Geousp, São Paulo, v. 17, p. 135-151, 2005.

SANTOS, C. M. D.; AMORIM, D. S. Why biogeographical hypotheses need a well supported phylogenetic framework: a conceptual evaluation. Papéis Avulsos de Zoologia, São Paulo, v. 47, n. 4, p. 63-73, 2007.

SVMA

Onça-parda.

Disponível em:<http://www.prefeitura.sp.gov.br/cidade/secretarias/upload/chamadas/poster 13 oncaparda 1275928336.pdf>. Acesso em: 22/02/2011.

USSARTF.

Animal

tracking.

Disponível em:<http://www.ussartf.org/animal tracking.htm>. Acesso em: 22/02/2011.

VIELLIARD, J. M. E. Advances in Bioacoustics. Anais da Academia Brasileira de Ciências, Rio de Janeiro, v. 76, n. 2, p. 188-189, 2004.

WAKE, D. B.; VREDENBURG, V. T. Are we in the midst of the sixth mass extinction? A view from the world of amphibians. Proceedings of the National Academy of Sciences, Washington, v. 105, n. 1, p. 11466-11473, 2008.

WATTS, D. Principles of Biogeography. London: McGraw-Hill, 1971.

ZUNINO, M.; ZULLINI, A. Biogeografía: la dimensión espacial de la evolución. Ciudad de México: FCE, 2003. 